\title{
Seasonal variability in voluntary dive duration of the Mediterranean loggerhead turtle, Caretta caretta*
}

\author{
FLEGRA BENTIVEGNA, SANDRA HOCHSCHEID and CARMEN MINUCCI \\ Stazione Zoologica “Anton Dohrn”, Villa Comunale 1, 80121 Napoli, Italy. E-mail: flegra@alpha.szn.it
}

\begin{abstract}
SUMMARY: We characterised the effect of seasonal fluctuations in water temperature $\left(T_{w}\right)$ on the nonventilatory period (NVP) of Mediterranean loggerhead turtles, Caretta caretta. Ten captive turtles, that were subject to the natural variations in $\mathrm{T}_{\mathrm{w}}$ found in the Gulf of Naples, dived significantly longer when $\mathrm{T}_{\mathrm{w}}$ decreased. More than $50 \%$ of summer and winter dives lasted between 2 and $10 \mathrm{~min}$; the maximum dive duration $(120 \mathrm{~min})$ occurred in winter at a $\mathrm{T}_{\mathrm{w}}$ of $13^{\circ} \mathrm{C}$. The longest NVP coincided with a low level of activity and a lower food consumption. This, and a reduced metabolic rate consequent to acclimatisation to a low $\mathrm{T}_{\mathrm{w}}$ were likely to have influenced NVP.
\end{abstract}

Key words: dive duration, temperature effect, sea turtle, season, apnoea.

RESUMEN: VARIABILIDAD ESTACIONAL EN LA DURACIÓN VOLUNTARIA DE LA INMERSIÓN EN LA TORTUGA BOBA MEDITERRÁNEA, CARETTA CARETTA. - En el presente estudio se caracterizó el efecto de la fluctuación estacional en la temperatura del agua $\left(\mathrm{T}_{\mathrm{w}}\right)$ sobre el periodo no ventilatorio (NVP) de la Tortuga Boba del Mediterráneo, Caretta caretta. Diez tortugas mantenidas en cautividad fueron sometidas a las variaciones naturales de la $T_{w}$ del Golfo de Nápoles, la inmersión fue significativamente más larga cuando la $\mathrm{T}_{\mathrm{w}}$ decrecía. Más del $50 \%$ de las inmersiones, tanto en verano como en invierno, duraron entre 2 y 10 minutos; la inmersión de máxima duración (120 minutos) ocurrió en invierno a una $\mathrm{T}_{\mathrm{w}}$ de $13^{\circ} \mathrm{C}$. El más largo NVP coincidió con el bajo nivel de actividad y el menor consumo de alimento. Ésto, y el reducido grado metabólico como consecuencia de la aclimatación a la baja $\mathrm{T}_{\mathrm{w}}$ probablemente influyeron en el NVP.

Palabras clave: tiempo de inmersión, efecto de temperatura, tortuga marina, apnea.

\section{INTRODUCTION}

Air-breathing animals that have adopted a subaquatic life style face major constraints due to the lack of adequate gas-exchange organs. For this reason they have to return to the water surface after an apneic period to replenish their oxygen stores and unload the accumulated carbon dioxide. The time that these animals can spend underwater between two successive surfacing events is affected by such factors as body mass, metabolic rate and temperature (Kooy-

*Received December 17, 2002. Accepted April 4, 2003. man, 1989; Handrich et al., 1997). The latter has been shown to be an important factor in directing the vital activities of sea turtles, which are the major reptilian representatives in marine ecosystems (Mrosovsky, 1980). Because of their low metabolic rate and thus, oxygen consumption, sea turtles can stay submerged for longer periods than most avian and mammalian divers. Moreover, when water temperature decreases, the metabolic rate of sea turtles decreases, thereby enabling them to stay in apnoea for prolonged periods (Lutz et al., 1989). Consequently, the surfacing behaviour of marine turtles should vary in response to seasonal temperature changes. 
The Mediterranean Sea is a unique habitat as it resembles an almost closed water basin. Sea turtles are believed to stay within the Mediterranean during the winter months, but they migrate extensively between summer and winter habitats. Changes in water temperature may trigger the migratory behaviour (Bentivegna and Paglialonga, 1998). Nevertheless they encounter lower temperatures in the winter than in the summer (annual range: $13-26^{\circ} \mathrm{C}$ ). The aim of this study was to characterise the seasonal variation in sea turtle diving behaviour. This is the first long-term study of the diving intervals of the Mediterranean loggerhead turtle, Caretta caretta, conducted under natural temperature regimes that reflect the seasonal changes in the Gulf of Naples, Italy.

\section{MATERIALS AND METHODS}

Ten juvenile loggerhead turtles with a body mass ranging between 1.6 and $19.8 \mathrm{~kg}$ were studied (Table 1). They were kept individually in either 200 1 rectangular tanks ( $\mathrm{L}$ x W x H: 80 x $60 \times 40 \mathrm{~cm}$ ) or 20001 round tanks (diameter: $160 \mathrm{~cm}$, height: 80 $\mathrm{cm}$ ) that were supplied with natural sea water from the Gulf of Naples via a semiclosed circulation system. Thus, the turtles were subject to the seasonal variations of water temperature that occur in the Gulf of Naples (Fig. 1). These temperatures were measured routinely each day in the basin containing the water which was pumped from the sea. All turtles had been stranded in Italian waters and were brought to the Aquarium of the Stazione Zoologica "Anton Dohrn" (Naples, Italy) to recover and, if necessary, for veterinary treatment. At the time of the observations all turtles were in apparent good health. They were fed fresh anchovies and/or de-frozen

TABLE 1. - Date of arrival in the Aquarium of Naples, curved carapace length (CCL) at the date of arrival and body mass (BM) of the 10 loggerhead turtles, Caretta caretta.

\begin{tabular}{lccc}
\hline individual no. & arrival date & CCL [cm] & $\begin{array}{c}\text { BM [kg] } \\
\text { (Feb'94-Sep'94) }\end{array}$ \\
\hline 1 & 20.05 .1992 & 47.0 & $17.0-19.6$ \\
2 & May 1992 & 32.0 & $7.5-9.1$ \\
3 & 13.08 .1992 & 45.0 & $16.0-18.6$ \\
4 & 30.08 .1992 & 37.0 & $15.6-19.8$ \\
5 & 02.05 .1993 & 30.0 & $4.3-5.1$ \\
6 & 08.09 .1993 & 27.0 & $3.2-4.4$ \\
7 & 21.12 .1993 & 41.5 & 8.1 \\
8 & 30.12 .1993 & 37.0 & $5.6-6.2$ \\
9 & 04.05 .1994 & 33.5 & $4.1-4.5$ \\
10 & 14.05 .1994 & 25.0 & $1.6-2.3$ \\
\hline
\end{tabular}

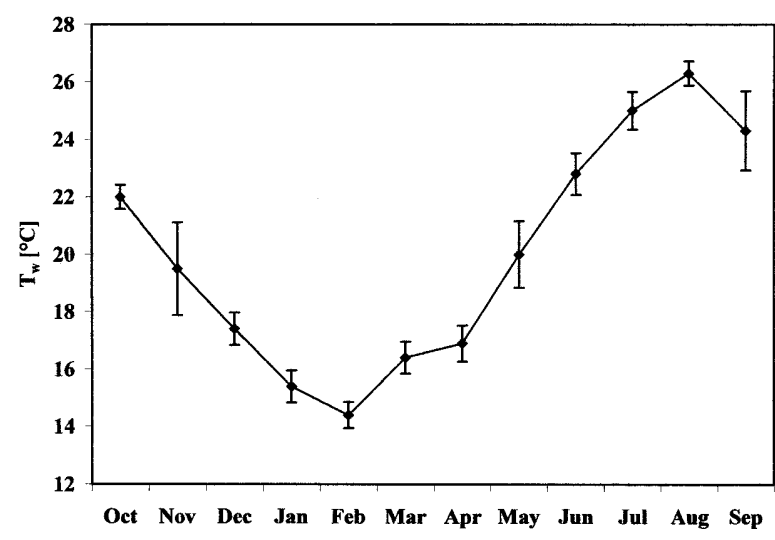

FIG. 1. - Monthly mean water temperature $T_{w}$ in the Gulf of Naples during the study period. Error bars are the standard deviation of the mean.

squid and, except for turtle no. 7 (see Table 1), gained body mass during the study.

Observations of voluntary dive time were made in the winter from January 1994 through March 1994 and in the summer from June 1994 through August 1994. Of the 10 turtles, 6 were observed in both the summer and winter, and the other 4 were observed only in the summer. During both seasons, each turtle was observed every third day for an average of 90 min (see Lutcavage and Lutz, 1991). During each of these observations the dive duration (for dives exceeding $2 \mathrm{~min}$ ) was measured to the nearest second using a stop watch, and water temperature was measured using a mercury thermometer (Goldbrand, Anschütz, Germany; resolution: $0.1{ }^{\circ} \mathrm{C}$ ).

\section{RESULTS}

A total of 428 observations were made, the diving behaviour of each turtle being studied for about 45 hours per season. Water temperature ranged from 13 to $17^{\circ} \mathrm{C}$ in winter and from 22 to $27^{\circ} \mathrm{C}$ in summer. In both winter and summer more than $50 \%$ of the NVP lasted between 2 and $10 \mathrm{~min}$. On the whole, NVP in the summer (when $\geq 22^{\circ} \mathrm{C}$ ) were shorter than in the winter. In summer dives did not exceed $40 \mathrm{~min}$, whereas in winter single dives of up to $120 \mathrm{~min}$ were recorded (Fig. 2). In contrast to summer dives, $18.8 \%$ of all winter dives lasted $\geq 40 \mathrm{~min}$.

To determine the relationship between dive duration and water temperature we considered the maximum dive duration of each of the 6 turtles at each temperature in the summer and the winter months, because during the longest dives all the turtles were in a comparable state of activity (i.e. resting on the 


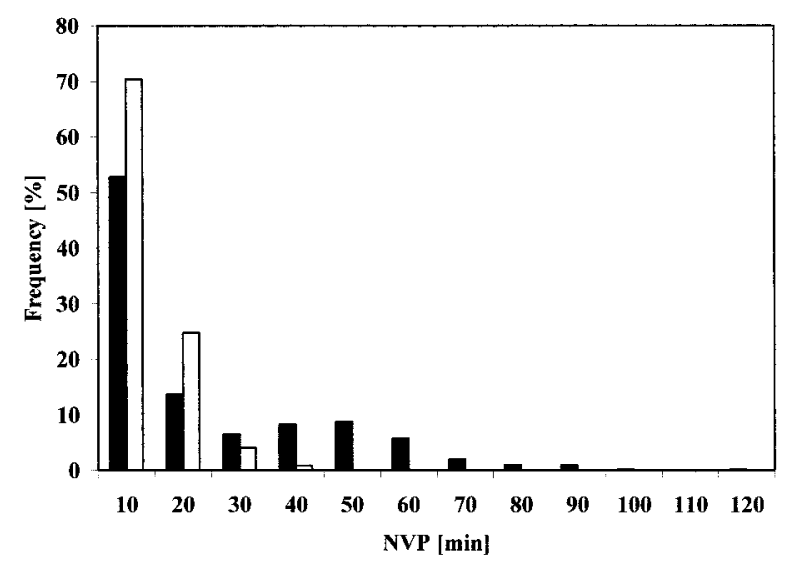

FIG. 2. - Frequency distribution of the dive duration of Mediterranean loggerhead turtles $(\mathrm{n}=10)$ during the summer period (open columns) and winter period (filled columns).

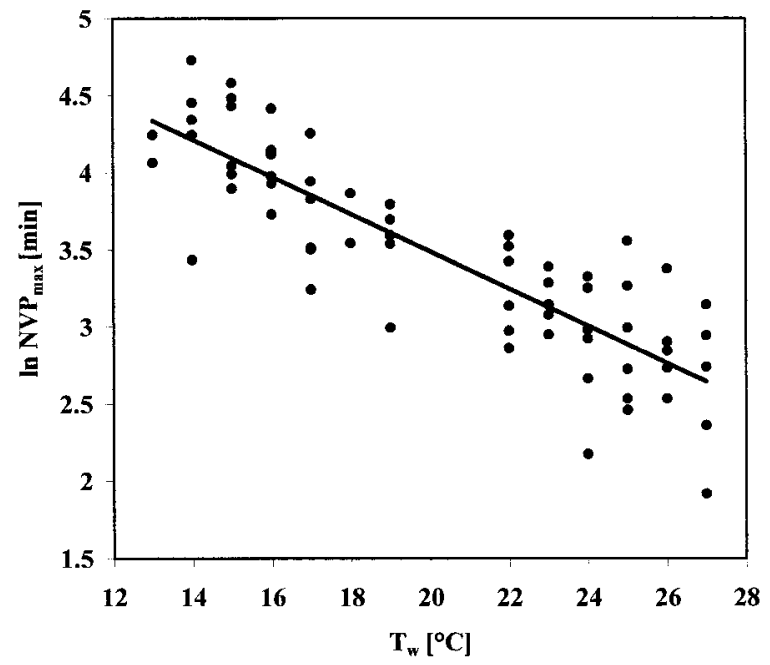

FIG. 3. - Maximum dive duration of loggerhead turtles $(n=6)$ at seasonal varying water temperatures $\mathrm{T}_{\mathrm{w}}$. Equation for linear regression line: $\ln \max \mathrm{NVP}=5.9-0.121 * \mathrm{~T}_{\mathrm{w}} ;\left(\mathrm{R}^{2}=0.73\right)$.

bottom of the tank). As water temperature increased towards the summer months, dive duration decreased. No significant effect of body mass on dive duration was found (multiple stepwise regression analysis on water temperature, dive duration and body mass: body mass was removed from the analysis; F-factor to remove: 4.0). Therefore we excluded body mass from the statistical analysis and conducted a linear regression analysis for dive duration and water temperature only, which proved that this relationship was highly significant (ANOVA: $\mathrm{F}_{1,64}=171.86, \mathrm{P}<0.001$; Fig. 3).

\section{DISCUSSION}

Because of the difficulty of observing sea turtles in the wild, several questions about their diving behaviour remain largely unanswered. Investigations using transmitting- or data-logging devices attached to the turtle's carapace are undertaken mainly during the nesting season, when the females go on land to lay eggs (e.g. in the Mediterranean: Hochscheid et al., 1999; Houghton et al. 2002). However, information about their movements and preferred locations during the winter are mainly derived from occasional sightings or fisheries bycatch (but see Epperly et al., 1995). This is also the case for the Mediterranean (Laurent and Lescure, 1994). Our study is the first attempt to determine seasonally induced variations in voluntary dive duration of Mediterranean loggerhead turtles.

Although our findings were obtained from captive turtles, the conditions mimic natural sea water conditions, because the water in the tanks underwent the same temperature fluctuations as the water in the Gulf of Naples. Moreover, all 10 turtles originated from the area around the southern west coast of Italy and they had been in captivity for a very short time of their life. Thus, it can be assumed that their behaviour was affected only by the confined space of the tanks, not by the conditions of the surrounding medium. Houghton et al. (2002) also found that inter-nesting loggerhead turtles from Cyprus, Eastern Mediterranean, generally dived for less than 40 min in water of 27 to $28^{\circ} \mathrm{C}$. The dive duration observed in this study may therefore reflect closely the seasonal variations in dive duration of free-ranging loggerhead turtles. It has to be considered, however, that free-ranging loggerhead turtles might move away from South Italian waters when temperatures become low (Bentivegna, 2002). But even if they do so they still encounter seasonal temperature variations in other regions of the Mediterranean basin. To date it cannot be said with certainty whether loggerhead turtles are present in the Bay of Naples and surrounding area all year or whether they leave during the winter. There are actually indications for both derived from turtle sightings in the winter months (CSC, 2000; 2001) and from satellite tracking studies (Bentivegna, 2002).

There are no other temperature-related dive times of free-ranging Mediterranean loggerhead turtles in the literature with which to compare our results. However, captive loggerhead turtles kept in sea water of 22 to $25^{\circ} \mathrm{C}$ originating from Biscayne Bay, Florida also dived between 5 and 40 min (Lutcavage and Lutz, 1991). In winter, dive times were longer but also more variable, and included single dives that lasted almost 2 hours. Similar observations were 
made for green turtles, Chelonia mydas, and Kemp's ridley turtles, Lepidochelys kempi (Moon et al., 1997). The increase in dive duration with decreasing water temperature probably resulted directly from reduced oxygen consumption, and thus a lower metabolic rate, at low temperatures (Lutz et al., 1989). Seasonal depression of metabolic rate has also been reported for terrestrial reptiles as, for example, the lizard, Lacerta vivipara jacquin, (Vandamme et al., 1991) or the fan-fingered gecko, Ptyodactylus hasselquistii, (Zari, 1999). In Vandamme's study, variation in temperature did not only affect metabolic rate, but also activity, feeding rate, mass change, etc. Despite food availability the turtles in this study consumed less at low temperatures than at high temperatures, which also relates to a high seasonal variation of growth rates (Bentivegna et al., unpublished data). Therefore, in addition to the seasonal metabolic rate depression, heat increment following feeding was probably also reduced, minimising the oxygen consumption even more.

Finally, as can be seen from the long resting dives, the loggerhead turtles were also less active at low temperatures (see also Moon et al., 1997). This recalls the often reported temperature effect on activity and food consumption in ectotherm animals (Schmidt-Nielsen, 1990), and could suggest that sea turtles in the wild enter a kind of winter dormancy during which energy requirements are minimal. However, such a dormant state has never been established under laboratory conditions (Moon et al., 1997) nor are data of wild turtles sufficient to support this often postulated hypothesis (Felger et al., 1976; Carr et al., 1980). The lack of data of overwintering sea turtles clearly shows that more investigations are needed to understand the energy regulations in these marine reptiles.

There was no size-related variation in dive duration in our turtles, but it is nevertheless possible that dive time scales with body mass. Different sized turtles have different lung capacities and, thus different total oxygen stores. The rate of oxygen consumption is also likely to be higher in smaller turtles than in larger ones. Moreover, dive time is also a function of dive depth. In fact, turtles take a larger lung volume $\left(\mathrm{O}_{2}\right.$ store $)$ down to deeper depths to achieve neutral buoyancy (Hays et al., 2000). Free living turtles may therefore dive for relatively long periods also in warm water conditions if the dives are sufficiently deep (G. C. Hays, personal communication). Our turtles could not select the depth of dives. Therefore we can assume that the individual turtles maintained a constant lung volume throughout the study when resting on the bottom of the tank. The same volume of air provides the turtle for longer time with oxygen in the winter than in the summer for the reasons discussed above.

In conclusion, the longer dive duration of loggerhead turtles in the winter can be explained as a response to multiple factors, mainly the depression of metabolic rate, activity and food intake, which are all related to a yet unknown extent. These behavioural and physiological adjustments reflect an acclimatisation to periods when energy resources are scarce, and thus have to be saved.

\section{ACKNOWLEDGEMENTS}

We thank the researchers of the Stazione Zoologica "Anton Dohrn" for their patience during this study when the turtles occupied most of the workspace in the stabulario. We acknowledge the helpful comments of Jean Anne Gilder and two anonymous referees on earlier versions of the manuscript.

\section{REFERENCES}

Bentivegna, F. - 2002. Intra-mediterranean migration of loggerhead sea turtles monitored by satellite telemetry. Mar. Biol., 141: 795-800.

Bentivegna, F. and A. Paglialonga. - 1998. Identification of the Gulf of Naples as a feeding ground and migratory path for Caretta caretta in the Mediterranean Sea. Proceedings of the $18^{\text {th }}$ International Sea Turtle Symposium 3-7 March 1998 , Mazatlán, Mexico, NOAA Technical Memorandum NMFSSEFSC, 436: 95-97.

Carr, A., L. Ogren and C. McVea. - 1980. Apparent hibernation by the Atlantic loggerhead turtle Caretta caretta off Cape Canaveral, Florida. Biol. Conserv., 19: 7-14.

CSC (Centro Studi Cetacei). - 2000. Tartarughe marine recuperate lungo le coste italiane. F. Bentivegna (compiler) In: Rendiconto 1998 (Reptilia). Atti. Soc. It. Sci. Nat., Museo Civ. Stor. Nat. Milano, 141: 145-158.

CSC (Centro Studi Cetacei). - 2001. Tartarughe marine recuperate lungo le coste italiane. II. Rendiconto 1999 (Reptilia). F. Bentivegna (compiler). Atti. Soc. It. Sci. Nat. Museo civ. Stor. Nat. Milano, 142: 265-281.

Epperly, S.P., J. Braun, A.J. Chester, F.A. Cross, J.V. Merriner and P.A. Tester. - 1995. Winter distribution of sea turtles in the vicinity of Cape Hatteras and their interactions with the summer flounder trawl fishery. Bull. Mar. Science, 56: 547-568.

Felger, R.S., K. Cliffton and P.J. Regal. - 1976. Winter dormancy in sea turtles: independent discovery and exploitation in the Gulf of California by two local cultures. Science, 191: 283-285.

Handrich, Y., R.M. Bevan, J.-B. Charrassin, P.J. Butler, K. Pütz, A.J. Woakes, J. Lage and Y. Le Maho. - 1997. Hypothermia in foraging king penguins. Nature, 388: 64-67.

Hays, G.C., C.R. Adams, A.C. Broderick, B.J. Godley, D.J. Lucas, J.D. Metcalfe, and A.A. Prior. - 2000. The diving behaviour of green turtles at Ascension Island. Anim. Behav., 59: 577-586.

Hochscheid, S., B.J. Godley, A.C. Broderick and R.P. Wilson. 1999. Reptilian diving: highly variable dive patterns in the green turtle, Chelonia mydas. Mar. Ecol. Progr. Ser., 185: 101-112.

Houghton, J.D.R., A.C. Broderick, B.J. Godley, J.D. Metcalfe and G.C. Hays. - 2002. Diving behaviour during the internesting 
interval for loggerhead turtles Caretta caretta nesting in Cyprus. Mar. Ecol. Progr. Ser., 227: 63-70.

Kooyman, G. L. - 1989. Diverse Divers. Springer, Berlin.

Laurent, L. and J. Lescure. - 1994. The wintering of the Mediterranean loggerhead turtle Caretta caretta (L) in southern Tunisia. Rev. Ecol. (Terre et Vie), 49: 63-86.

Lutcavage, M.E. and P.L. Lutz. - 1991. Voluntary diving metabolism and ventilation in the loggerhead sea turtle. J. Exp. Mar. Biol. Ecol., 147: 287-296.

Lutz, P.L., A. Bergey and M. Bergey. - 1989. Effects of temperature on gas exchange and acid-base balance in the sea turtle Caretta caretta at rest and during routine activity. J. Exp. Biol., 144: 155-169.

Moon, D.Y., D.S. MacKenzie and D.W. Owens. - 1997. Simulated hibernation of sea turtles in the laboratory. 1. Feeding, breath- ing frequency, blood $\mathrm{pH}$, and blood gases. J. Exp. Zool., 278: 372-380.

Mrosovsky, N. -1980 . The thermal biology of sea turtles. Amer. Zool., 20: 531-547.

Schmidt-Nielsen, K. - 1990. Animal Physiology - Adaptation and Environment, 4th ed. Cambridge University Press, Cambridge

Vandamme, R., D. Bauwens and R.F. Verheyen. - 1991. The thermal dependence of feeding behavior, food consumption and gut passage time in the lizard Lacerta vivipara jacquin. Funct. Ecol., 5: 507-517.

Zari, T.A. - 1999. Seasonal acclimatization in metabolic rate of the fan-fingered gecko, Ptyodactylus hasselquistii (Reptilia: Gekkonidae). J. Therm. Biol., 24: 137-142.

Scient. ed.: P. Abelló 
